\title{
Pressure Drop Determination for Multiphase Flow in a Vertical Well Tubing
}

\author{
Sarah A Akintola,* Olakunle F \\ Department of Petroleum Engineering, University of Ibadan, Ibadan Oyo State Nigeria
}

\begin{abstract}
Several studies have been carried out, by researchers to predict multiphase flow pressure drop in the oil and gas industry, but yet there seems to be one being generally acceptable for accurate prediction of pressure drop. This is as a result of some constraints in each of these models, which makes the pressure drop predicted by the model far from accurate when compared to measured data from the field. This study is aimed at developing a multiphase fluid flow model in a vertical tubing using the Duns and Ros flow model. Data from six wells were utilized in this study and results obtained from the Modified model compared with that of Duns and Ros model along other models. From the result, it was observed that the newly developed model (Modified Duns and Ros Model) gives more accurate result with a R-squared value of 0.9936 over the other models. The Modified model however, is limited by the choice of correlations used in the computation of fluid properties.
\end{abstract}

Keywords: Duns and Ros model, Modified duns and Ros flow model multiphase flow, Multiphase pressure drops

\section{Introduction}

Multiphase flow is a common occurrence in the petroleum, chemical and process, space, geothermal energy plant, air-conditioning system and nuclear reactor industries. The need to study multiphase flow in these industries arises for a number of reasons which include; proper design and safety purposes. The polyphasic flow of Newtonian fluids in vertical pipes has been investigated both theoretically and experimentally by several researchers. ${ }^{1-3}$ While others dealt with the problem of predicting pressure gradients in an oil wells, where the flowing fluid may be gas, oil or water mixture with interphase mass transfer. The complexity of fluids encountered, the large diameters, long lengths of pipe and often times in hostile environments, make multiphase flow unique in the petroleum industry ${ }^{4}$.

The essence of multiphase flow studies in the petroleum industry is to determine the pressure drop in pipes (vertical, horizontal or inclined). Several approaches have been used to achieve the best method to obtain accurate prediction of pressure drops in pipes. The methods used to predict pressure gradient can be classified as empirical correlations and mechanistic models (Table 1). These correlations are based on experiments performed mostly in the laboratory.

The large variation in pressure and temperature along a wellbore suggests that different flow patterns would exist at various depths ${ }^{5}$ Crude oil usually enters the wellbore as a single phase, but as the fluid moves upward, pressure decreases gradually and gas will evolve from liquid and bubble flow starts. Flow pattern is the various configurations that exist as interface between different phases in a multiphase fluid flow in the wellbore or pipeline. These flow patterns have been described by different investigators as internal structures or interface existing between the phases present in a multiphase flow. They are usually obtained from flow pattern maps (empirically or mechanistic model). In some cases, these flow

\begin{tabular}{|l|l|}
\hline \hline Quick Response Code: & *Corresponding author: Sarah A Akintola, Department of Petroleum Engineering, University of \\
Ibadan, Ibadan Oyo State Nigeria
\end{tabular}


patterns are subjective based on the visual observation of the investigator ${ }^{6}$ from the dimensional or dimensionless parameters deduced from experiments.

The four major flow patterns for vertical flow in pipes: bubble flow (bubbles of gas of small sizes present in liquid), slug/plug flow (large gas mass formed from the merged individual gas bubbles), churn flow (the slugs begin to disintegrate due to changes in phase flow rates) and annular flow (the gas flows in the middle of the pipe, while the liquid phase occupies the space adjacent to the pipe wall) ${ }^{7}$ were described by as presented in the Figure 1 .

Table 1: Empirical Correlations.

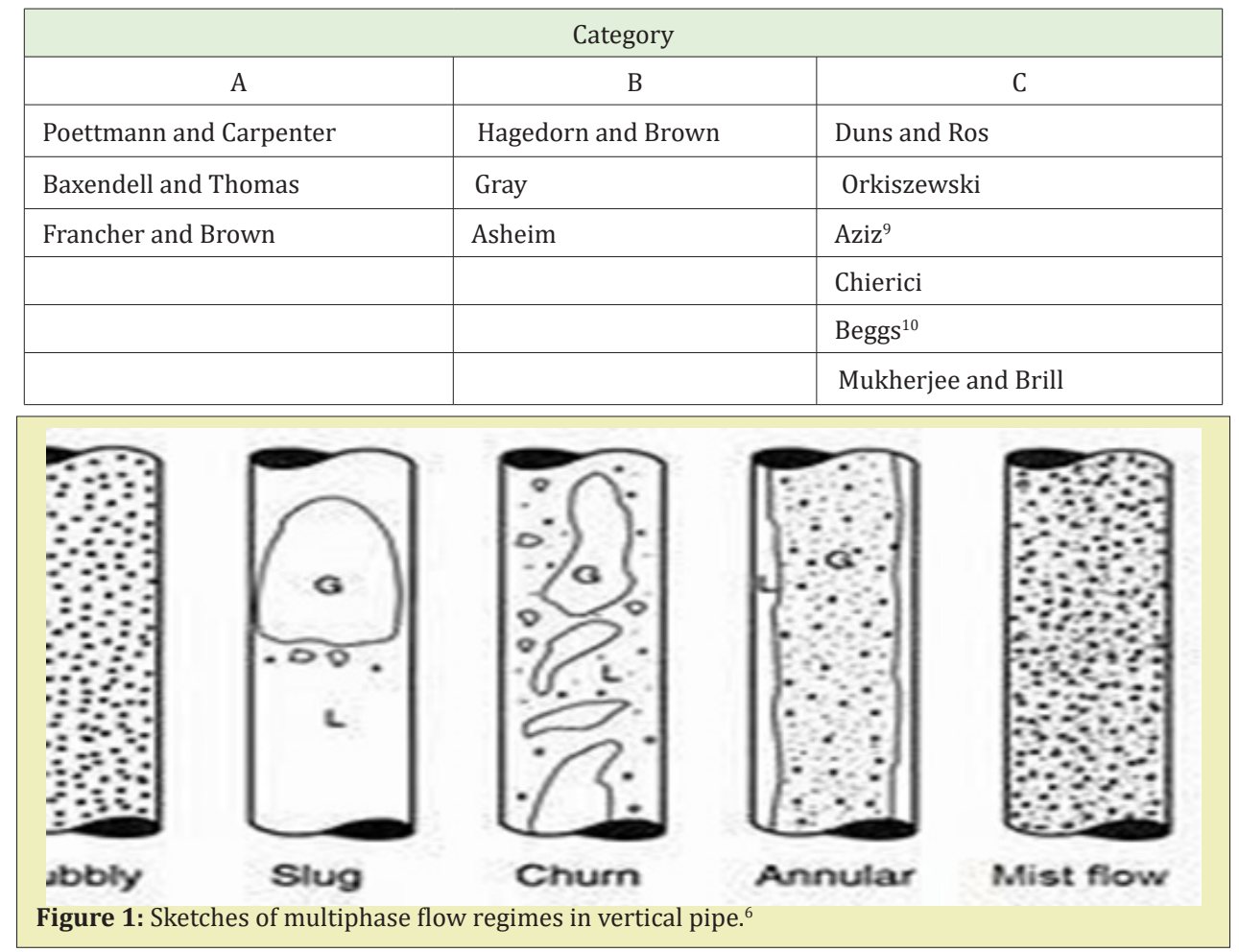

The sand-grain ${ }^{7}$ experiments formed the basis for friction factor data for rough pipes wall is given as equation 1.0.

$$
\frac{1}{\sqrt{f}}=1.74-2 \log \left(\frac{2 \varepsilon}{d}\right)
$$

An empirical equation 2.0 to describe the variation of $f$ in the transition region was proposed ${ }^{8}$. It has become the basis for modern friction factor charts

$$
\frac{1}{\sqrt{f}}=1.74-2 \log \left(\frac{2 \varepsilon}{d}+\frac{18.7}{N_{R e} \sqrt{f}}\right)
$$

Solving equation 1.0 for $f$ requires a trial and error process. Equation 3.0 can be expressed as

$$
f_{c}=\left[1.74-2 \log \left[2\left(\frac{\varepsilon}{d}\right)+\frac{18.7}{\left(N_{R e}\right)_{n} \sqrt{f \mathrm{est}}}\right]\right]^{-2}
$$

Values of $f$ are estimated, $f$ est and then calculated, $f_{c}$, until they agree to within an acceptable tolerance. The pressure gradient equation for single phase flow can be modified for multiphase flow by considering the fluid to be a homogeneous mixture, hence equation 4.0

$$
\left(\frac{d p}{d L}\right) t=f_{t p} \rho V^{2} / 2 g D+\frac{g}{g_{c}} \rho_{m} \sin \theta+\frac{\rho V_{m}}{g_{c}} \frac{D V_{m}}{d L}
$$

Where the definition for $\rho$ and $V_{m}$ can vary with different investigators. For vertical flow, $\sin \theta=1, d L=d z$ and the equation can be written as shown in the equation 5.0

$$
\left(\frac{d p}{d z}\right) t=\left(\frac{d p}{d z}\right) e l+\left(\frac{d p}{d z}\right) f+\left(\frac{d p}{d z}\right) a c c
$$

Except for conditions of high velocity, most of the pressure drop in vertical flow is caused by this component. The pressure drop caused by acceleration is normally negligible and is considered only for cases of high flow velocities. Many methods have been developed to predict two-phase flowing pressure gradients. This study presents a modified Duns and Ros Model for predicting pressure drop in a gas, oil and water 3-phase flow in vertical pipes. These models will combine three empirical correlations; Duns and Ros $^{2}$. model for selecting the flow regimes, Aziz, et al. ${ }^{9}$ model to account for the Liquid hold up and the Beggs and Brills model ${ }^{10}$ method of calculating the two-phase friction factor. 
The input volume fractions for liquid and gas in -situ volume fraction are defined as expressed in the equations $6.0 \mathrm{a}$ and $16.0 \mathrm{~b}$, respectively. $q_{l}$
$\lambda_{L}=\frac{q_{l}+q_{g}}{}$ $6.0 \mathrm{a}$

$$
\stackrel{\text { and }}{\lambda_{g}}=\frac{q_{g}}{q_{l}+q_{g}}
$$

Where,

$\lambda_{L \text { and }} \lambda_{g}=$ In-situ liquid and gas volume fraction , respectively

$q_{l \text { and }} q_{g}=$ Liquid and gas flow rate at prevailing pressure and Temperature (bbl/d, respectively

The input volume fractions, $\lambda_{L}$ and $\lambda_{g}$ are also referred to as the 'no slip holdups'.

In-situ Volume fraction (Liquid Holdup Effect): With the in-situ volume fraction of the denser and lighter liquid phase are expressed in the equations $7.0 \mathrm{a}$ and $7.0 \mathrm{~b}$

$$
H_{L}=\frac{V_{L}}{V}
$$

while the in-situ volume fraction of the lighter gas phase is defined as

$$
H_{g}=\frac{V_{g}}{V}
$$

Where,

$H_{L}$ and $H_{g}=$ In-situ liquid and gas volume fraction, respectively.

$V_{L}$ and $V_{g}=$ =Volume of liquid and gas phase in pipe segment (cubic feet), respectively

$V=$ Volume of the pipe segment (cubic feet)

If the gas is completely occupied by the phases equation 8.0 applies,

$$
H_{g}=1-H_{L}
$$

The in-situ volume fraction or Liquid holdup is often estimated from the multiphase (Empirical or mechanistic) correlations.

The Slip Velocity is expressed mathematically as presented in the equation 9.0

$$
v_{s}=\bar{v}_{g}^{-}-\bar{v}_{l}
$$

\section{where}

$v_{S}=\operatorname{Slip}$ velocity $(\mathrm{ft} / \mathrm{s})$

${ }^{-} \overline{\bar{v}}_{L}$ and ${ }^{-} \bar{v} \bar{g}=$ Average in-situ velocity of liquid and gas (ft/s), respectively

The superficial velocity of each phase is expressed mathematically as shown in the equations. 10.0 and 11.0

For the liquid phase,

$$
v_{s L}=\frac{4 q_{l}}{\pi D^{2}}
$$

For the gas phase,

$$
v_{s g}=\frac{4 q_{g}}{\pi D^{2}}
$$

Where,

$v_{s L \text { and }} v_{s g}=$ Superficial liquid and gas velocity $(\mathrm{ft} / \mathrm{s})$, respectively

$q_{l \text { and }} q_{g}=$ Liquid flow rate at prevailing pressure and Temperature (bbl/D), $q_{g}$

$D=$ Pipe Diameter $(\mathrm{ft})$

The average in-situ velocities, ${ }^{-} \bar{v}_{g}^{-}$and ${ }^{-} \bar{v}_{L}^{-}$are related to the superficial velocities and the in-situ fractions by the following equations 12.0 and 13.0 .

$$
\begin{aligned}
& \overline{v_{g}}=\frac{v_{s g}}{H_{g}} \\
& \overline{v_{L}}=\frac{v_{s L}}{H_{L}}
\end{aligned}
$$

Therefore, the slip velocity is presented in the equation $14.0 \mathrm{y}$,

$v_{s}=4 / \pi D^{2}\left[\frac{q_{g}}{1-H_{L}}-\frac{q_{L}}{H_{L}}\right]$

The input volume fraction is related to the superficial velocity by the following equation 15.0 and 16.0 ,

$$
\begin{aligned}
& \lambda_{L}=\frac{v_{s L}}{v_{m}} \\
& \lambda_{L}=\frac{v_{s g}}{v_{m}}
\end{aligned}
$$

Where;

$v_{m}=$ Mixture velocity(ft/s)

The Mixture Density is expressed in the equations 17.0

$\rho_{\mathrm{m}}=\rho_{\mathrm{L}} \mathrm{H}_{\mathrm{L}}+\rho_{\mathrm{g}}\left(1-\mathrm{H}_{\mathrm{L}}\right)$

Where,

$\rho_{\mathrm{m}}=$ Mixture density (lbf/cu.ft)

$\rho_{\text {Land }} \rho_{g}=$ Liquid and Gas density (lbf/cu.ft), respectively

$\mathrm{H}_{\mathrm{L}}=\mathrm{In}$-situ liquid volume fraction

The mixture velocity is given by equation 19.0

$v m=v s L+v s g$ 18.0

Where,

$v_{m}=$ mixture velocity $(\mathrm{ft} / \mathrm{s})$

$v_{S L}$ and $v_{S g}=$ Superficial liquid and gas velocity (ft/s), respectively

The mixture viscosity is expressed as showned in the equation 19.0

$\mu_{m}=\mu_{L} H_{L}+\mu_{g}\left(1-H_{L}\right)$ 19.0 
Where,

$\mu_{m}=$ mixture viscosity (cp)

$\mu_{L}$ and $\mu_{g=\text { Liquid viscosity (cp) }}$

$\mathrm{H}_{\mathrm{L}}=\mathrm{In}$-situ gas volume fraction

The no-slip density is defined in the equation 20.0 as follows

$\rho_{n}=\rho_{L} \lambda_{l}+\rho_{g} \lambda_{g}$

Where,

$\rho_{n=\text { no-slip density (lb/cu.ft) }}$

$\rho_{L \text { and }} \rho_{g=\text { Liquid and gas density (lb/cu.ft) }}$

$\lambda_{L \text { and }} \lambda_{g}=$ In-situ liquid and gas volume fraction

The no-slip viscosity calculated with the equation 21.0

$\mu_{n}=\mu_{L} \lambda_{l}+\mu_{g} \lambda_{g}$

Where,

$\mu_{n=\text { No slip viscosity (cp) }}$

$\mu_{L \text { and }} \mu_{g=\text { Liquid and Gas viscosity (cp) }}$

$\lambda_{\text {Land }} \lambda_{g}=$ In-situ liquid and gas volume fraction

\section{Methodology}

The general energy equation (equation 22.0), is the theoretical basis for most fluid flow equations, and most mechanistic models and multiphase correlations which can be used for estimating pressure gradient in a producing well are derived from it.

$U_{1}+P_{1} V_{1}+\frac{m v_{1}^{2}}{2 g_{c}}+\frac{m g z_{1}}{g_{c}}+Q+W_{s}=U_{2}+P_{2} V_{2}+\frac{m v_{2}^{2}}{2 g_{c}}+\frac{m g z_{2}}{g_{c}}$

Where;

$\mathrm{U}=$ Internal energy of the fluid lbf- $\mathrm{ft}$

$\mathrm{P}=$ pressure, psia

$\mathrm{V}=$ Volume, cuft

$\mathrm{m}=$ mass of fluid, $\mathrm{lbm}$

$\mathrm{v}=$ average fluid velocity, $\mathrm{ft} / \mathrm{sec}$

$\mathrm{z}=$ distance in the vertical direction, $\mathrm{ft}$

$\mathrm{g}=$ acceleration due to gravity, $\mathrm{ft} / \mathrm{sec}^{2}$

$g_{c}=$ conversion factor $=32.17 \mathrm{lbm} \mathrm{ft} / \mathrm{lbf}-\mathrm{sec}^{2}$

$\mathrm{PV}=$ Pressure volume (Energy of compression or Expansion), lbf-ft $m v^{2}$

$\overline{2 g_{c}}=$ Kinetic energy of the fluid, lbf-ft

$\underline{m g z}$

$g_{c}=$ Potential energy of the fluid, lbf-f

$\mathrm{Q}=$ Energy added or removed from the fluid, lbf- $\mathrm{ft}$
$W_{s}=$ Shaft work done on the fluid by the surroundings (shaft work done by the fluid to the surroundings is negative), lbf-ft

The equation 23.0 gives an expression for the total pressure gradient for a vertical pipeline or tubing.

$$
\frac{\partial P}{\partial z}=-\left(\frac{\rho v \partial v}{g_{c} \partial z}+\frac{\rho g}{g_{c}}+2 f \rho V^{2} / g_{c} D\right)
$$

Where,

$\frac{\partial P}{\partial z}$

$\overline{\partial z}=$ Total pressure gradient, $\mathrm{lbf} / \mathrm{ft}^{3}$

$\frac{\rho g}{g_{c}}=$ Elevation or static pressure gradient, lbf $/ \mathrm{ft}^{3}$

$\frac{\rho v \partial v}{g_{c} \partial z}=$ Acceleration or Kinetic pressure gradient, lbf $/ \mathrm{ft}^{3}$

since $\frac{g}{g_{c}} \approx 1$, characterizing pressure drop associated with fluid flow in a vertical tubing, leads to the equation 24.0

$$
\frac{\partial P}{\partial z}=\frac{1}{144}\left(\frac{\rho v \partial v}{g_{c} \partial z}+\rho+2 f \rho V^{2} / g_{c} D\right)
$$

The introduction of the two phase friction factor, $f_{t p}$, gas liquid mixture density, $\rho_{m}$ and the gas-liquid mixture velocity (total fluid velocity), $V_{m^{\prime}}$, results in the equation 25.0

$$
\frac{\partial P}{\partial z}=\frac{1}{144}\left(\frac{\rho_{m} v_{m} \partial v_{m}}{g_{c} \partial z}+\rho+2 f_{t p} \rho_{m} V_{m}^{2} / g_{c} D\right)
$$

\section{The Model Development}

This model is aimed at the modification of Duns and Ros Model for modelling two phase flow in vertical pipes. This method combines the multiphase flow pattern criteria with the physical models for pressure drop and liquid holdup calculations for each of the flow patterns being considered. The Duns and Ros Model is modified with Aziz, et al. model used to determine the liquid hold up for bubble and slug flow regimes (Taylor bubble effect) with the liquid holdup calculation for mist flow calculated using Duns and Ros method. The Beggs and Brills method was used for calculating and estimating the friction factor

The following assumptions were made:

The flow is steady, isothermal, Newtonian, turbulent- $N_{R e}$ is more than 2100 and no work is done.

The acceleration/kinetic energy pressure gradient term in the energy equation and end effects is negligible

The fluid behaves as a continuum and pipe is a smooth pipe.

With the assumptions made above, the mechanical Energy Balance Equation can be in psi/ft as expressed in the equation 26.0

$$
\frac{\partial P}{\partial z}=\frac{1}{144}\left(\rho_{m}+2 f_{t p} \rho_{m} V_{m}^{2} / g_{c} D\right)
$$




\section{Flow Regime Determination}

The Duns and Ros model developed a map for flow pattern prediction, by identifying separate regions and dimensionless groups developed in their correlation to predict the flow patter ns

(Equations 27.0 a. 27.0b and 27.0c).

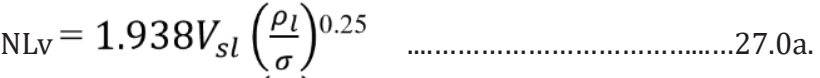

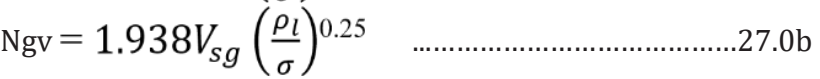

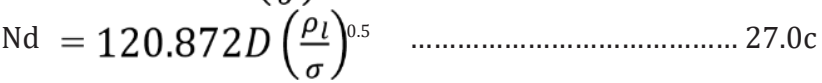

Where,

$\rho_{l}$ is the liquid mixture density in $\mathrm{lbm} / \mathrm{cu}-\mathrm{ft}$

$\sigma$ is the liquid mixture surface tension in dynes/cm

$\mathrm{D}$ is the flow diameter of the tubing in $\mathrm{ft}$

$V_{s l}$ and $V_{s g}$ are the liquid superficial and gas superficial velocities respectively.

In this study, the flow patterns considered are bubble, slug and mist (equations 28.0 a., 28.0b and 28.0c) type of flow

Bubble Flow

$0 \leq \mathrm{Ngv} \leq(\mathrm{L} 1+\mathrm{L} 2) \mathrm{NLV}$ 28.0a.

Slug Flow

$\left(\mathrm{L}_{1}+\mathrm{L}_{2}\right) \mathrm{N}_{\mathrm{Lv}}<\mathrm{N}_{\mathrm{gv}}<\left(50+36 \mathrm{~N}_{\mathrm{Lv}}\right)$ $28.0 \mathrm{~b}$

Mist Flow

$\mathrm{N}_{\mathrm{gv}}>\left(75+84 \mathrm{~N}_{\mathrm{gv}}^{0.75}\right)$ $28.0 \mathrm{c}$

\section{Pressure Gradient Determination}

The liquid holdup factor for bubble and slug types of flow was estimated using the equation 29.0 and the rise velocity of small gas bubbles in a flowing liquid calculated using the equation 30.0

$H_{L}=1-\frac{V_{s g}}{V_{b f}}$ 29.0

$V_{b f}$ is the rise velocity of small gas bubbles in a flowing liquid and can be calculated as follows

$V_{b f}=1.2 V_{m}+V_{b s}$ 30.0

Where,

$V_{b s}$, the rise velocity of a continuous swarm of small bubbles in a static liquid column

The mixture density is a function of liquid hold up $\mathrm{H}_{\mathrm{L}}$, given by equation 31.0

$\rho \mathrm{m}=\rho \mathrm{LHL}+\rho \mathrm{G}(1-\mathrm{HL})$ 31.0

Substituting equation 29.0 into 31.0 to obtain equation 32.0

$$
\rho_{m}=\rho_{g}+\left(\frac{V_{b f}-V_{s g}}{V_{b f}}\right)\left(\rho_{L}-\rho_{g}\right)
$$

The equation 33.0 is the modified model for estimating pressure gradient for bubble and slug types of flow in psi/ft

$\frac{\partial P}{\partial z}=\frac{1}{144}\left(\rho_{g}+\left(\frac{V_{b f}-V_{s g}}{V_{b f}}\right)\left(\rho_{L}-\rho_{g}\right)\right)\left(1+2 f_{t p} V_{m}^{2} / g_{c} D\right)$

For bubble flow: $V_{b s}$, the rise velocity of a continuous bubbles in a static liquid column in equation 34.0 is given by

$V_{b s}=1.41\left[\frac{\sigma g\left(\rho_{L}-\rho_{g}\right.}{\rho_{L}^{2}}\right]^{0.25}$

And for Slug flow, the rise velocity is presented in the equation 35.0

$V_{b s}=C \sqrt{\left[\frac{g D\left(\rho_{L}-\rho_{g}\right.}{\rho_{L}}\right]}$ .35 .0

Where $\mathrm{C}$ was given by Wallis as shown in the equation 36.0

$C=0.345\left[1-e^{\left(-0.029 N_{v}\right.}\right]\left[1-e^{\left(\frac{3.37-N_{E}}{m}\right.}\right]$

And
$N_{v}=\sqrt{\frac{D^{3} g \rho_{L}\left(\rho_{L}-\rho_{g}\right)}{\mu_{L}}}$

With $\mathrm{m}$ determined from the expression in the equation 38.0

$N_{v}$

$\mathrm{m}$

$\geq 250$

10

$250>N_{v}>18$

$69 N_{v}^{-0.35}$

$\leq 18$

25 ....38.0

\section{MIST FLOW}

Assume there is no slippage in the flow. i.e. $S=0$, the liquid-hold up is equation 39.0

$$
H_{L}=\frac{1}{1+\frac{V_{s g}}{V_{s l}}}
$$

\section{Two-Phase Friction Factor Determination}

To account for the no slip friction factor $f_{n}$. Payne, et al. $(1979)^{11}$ modifications to Beggs and Brills model was employed. A normalizing friction factor obtained from the Colebrook equation (40.0) was used with an iterative procedure used to obtain $f_{c}$

$f_{c}=\left[1.74-2 \log \left[2\left(\frac{\varepsilon}{d}\right)+\frac{18.7}{\left(N_{R e}\right)_{n} \sqrt{f \text { est }}}\right]\right]^{-2}$

Where,

$\frac{\varepsilon}{d}=$ Relative pipe roughness

$\mathrm{D}=$ Pipe diameter in $\mathrm{ft}$ 
$N_{R e}=$ no slip Reynolds number

For No slip Reynold's number, is obtained from the equation 41.0

$$
\left(N_{R e}\right)_{n}=\frac{G_{m} D}{\mu_{m}}
$$

And the friction factor ratio calculated with the equation 42.0

The friction factor ratio, $\frac{f_{t p}}{f_{n}}=e^{S}$

Then the slip factor,S is obtained calculated with the equation 43.0

$S=\frac{[\ln y]}{\left\{-0.0523+3.182[\ln y]-0.8725[\ln y]^{2}+0.01853[\ln y]^{4}\right\}}$

The equation 43.0 applies for $y \geq 1.2$

Where $y=\frac{\lambda_{l}}{\left[H_{L}\right]^{2}}$.

$H_{L}$ is the liquid hold up obtained for each flow regime

S becomes unbounded at a point in the interval $1>y<1.2$; for this interval the function $S$ is calculated from the equation 45.0:

$S=\ln (2.2 y-1.2)$ 45.0

Hence the two phase friction factor, equation 46.0

$f_{t p}=f_{n}\left(\frac{f_{t p}}{f_{n}}\right)$ 46.0
The Python program included in the Appendix A (along the additional correlation information used Appendix B) was developed to first select the flow regime with the given fluid, pipe and well properties using the boundaries previously stated then to evaluate the pressure drop at any depth using the Modelled pressure gradient formula given by the equation 33.0

\section{Results and Discussion}

With the Modified Model in place, a Python program was generated to carry out the computations. The program developed on Duns and Ros method to select the flow regimes that might occur in a vertical oil and Gas well at different rates of flow of fluid in the wellbore and also to evaluate the pressure drop at a given depth within that region. Fluid production data from six different wells (Table 2) were used in testing the model. The predictions were made based on the Modified model and Duns and Ros model and the data obtained were compared with measured data and then compared with some of the previous models Aziz, Ansari, Hagedorn and Brown, and Beggs and Brill as presented in the Table 3. The Relative Mean Square Error (RMSE), Mean Absolute Error (MAE) and the R-squared were estimated the for all the Models and presented in the Table $4 .{ }^{12}$

Table 2: The Data Employed for the Six Wells Being Examined.

\begin{tabular}{|l|l|l|l|l|l|l|l|l|l|}
\hline Well & $\begin{array}{l}\text { Pipe ID } \\
\text { Inches) }\end{array}$ & Well Depth, (ft) & WHP (psia) & $\begin{array}{l}\text { Avg Temp. } \\
(\mathbf{0} \mathbf{f})\end{array}$ & $\mathbf{Q}_{\mathbf{0}}$ (bbl/day) & $\mathbf{Q}_{\text {W }}$ (bbl/day) & GOR (scf/ bbl) & $\mathbf{S G}_{\mathbf{0}}$ & $\begin{array}{l}\text { Density of } \\
\mathbf{G a s}\end{array}$ \\
\hline A & 3.83 & 11373 & 2191 & 150 & 9922 & 0 & 1375 & 0.85 & 4.23 \\
\hline B & 2.441 & 7150 & 369 & 90 & 2201 & 0 & 78 & 0.93 & 0.65 \\
\hline C & 2.992 & 3890 & 670 & 110 & 1850 & 0 & 575 & 0.89 & 2.5043 \\
\hline D & 1.995 & 10184 & 820 & 90 & 2000 & 0 & 500 & 0.9 & 2.4258 \\
\hline E & 2.441 & 8010 & 210 & 90 & 800 & 200 & 160 & 0.9 & 0.59 \\
\hline F & 2.992 & 5151 & 505 & 90 & 1140 & 0 & 450 & 0.9 & 2.19 \\
\hline
\end{tabular}

Table 3: Test and Predicted Pressure Drop Results.

\begin{tabular}{|l|l|l|l|l|l|l|l|l|}
\hline Well & $\begin{array}{c}\text { WHP } \\
\text { (psia) }\end{array}$ & $\mathbf{\Delta P}$ (Measured) & $\boldsymbol{\Delta P}$ (Modified) & $\begin{array}{c}\Delta \mathbf{P}(\text { Duns } \\
\text { and Ros) }\end{array}$ & $\boldsymbol{\Delta P}$ (Aziz) & \multicolumn{1}{|c|}{ (Ansari) } & $\begin{array}{c}\Delta \mathbf{P} \text { Hagedorn } \\
\text { and Brown }\end{array}$ & $\Delta \mathbf{P}($ Beggs \& Brill) \\
\hline A & 505 & 1600 & 1656 & 1556.64 & 1738 & 1463 & 1529 & 1530.76 \\
\hline B & 210 & 2310 & 2364 & 2179.92 & 2280 & 2220 & 2530 & 2119.6 \\
\hline C & 820 & 3620 & 3587 & 3420.69 & 3560 & 3660 & 3830 & 3451.5 \\
\hline D & 670 & 760 & 747 & 787.24 & 750 & 640 & 950 & 771.95 \\
\hline E & 369 & 2594 & 2643 & 2677.09 & 2688 & 2510 & 2174 & 2784.1 \\
\hline F & 2191 & 3961 & 4039 & 4197.48 & 4341 & 3629 & 4203 & 4071.92 \\
\hline
\end{tabular}

Table 4: The Relative Mean Square Error, Mean Absolute Error and the R-Squared Values.

\begin{tabular}{|l|l|l|l|}
\hline \multicolumn{1}{|c|}{ MODELS } & \multicolumn{1}{c|}{ RMSE } & \multicolumn{1}{c|}{ MAE } & \multicolumn{1}{c|}{ R-SQUARED } \\
\hline Modified Model & 124 & 10.6 & 0.9936 \\
\hline Duns and Ros & 142 & 11 & 0.9916 \\
\hline Aziz & 171 & 10.9 & 0.9878 \\
\hline Ansari & 163 & 11.6 & 0.9889 \\
\hline Beggs and Brills & 140 & 11.1 & 0.9918 \\
\hline
\end{tabular}




\section{Conclusion}

With the helpful of python program, the pressure drop estimation process presented in this paper, is relatively easy and requires little computing time and absolutely cost effective when compared to the use of pressure gauges for pressure measurement in the field.

A distinction has to be made between the different flow regimes that might occur in a tubing/pipe, as this greatly affects the pressure gradient. Also, an in-depth knowledge of the multiphase flow variables, tubing properties and how they individually and collectively affect flow of fluids in pipes is necessary to ensure proper interpretations of the model.

The following observations were made during this study:

- The modified Model gave a mean absolute error of $10.6 \%$ while 11\% MAE was obtained from the original work of Duns and Ros. Hence, there is a reduction margin of error between the predicted pressure drop values using this model and measured values.

- It was observed that the model gives the most reasonable results for Pressure drop, when compared with the results obtained from other existing models available.

\section{Recommendation}

- More well data should be used in the analysis in order to validate the result of the model.

- Plots of different test data and variations in the dependent variables to establish empirical relationships between well head pressures and flowing bottom-hole pressures as estimated by the model.

Generally, an improved result is obtained with the use of the Modified Model in prediction when compared to the result obtained from the original work of Duns and Ros.

\section{Acknowledgments}

None.

\section{Funding}

None.

\section{Conflicts of Interest}

Author declares that there is no conflict of interest.

\section{References}

1. Poettmann PH, Carpenter PG. The Multiphase Flow of Gas, Oil and Water Through Vertical Flow Strings with Application to the Design and Gas-Lift Installations. Drill \& Prod Prac. 1952.

2. Duns H, Ros NCJ. Vertical Flow of Gas and Liquid Mixtures in Wells, Proc., $6^{\text {th }}$ : World Pet. Congo 1963, pp. 451.

3. Hagedorn AR, Brown KE. Experimental Study of Pressure Gradients Occurring During Continous Two-Phase Flow in Small Diameter Vertical Conduits. JPT. 1965;17(4):475-484.

4. Brill JP. Discontinuities in the Orkiszewski Correlation for predicting pressure Gradients in Wells. J Energy Res Tech. 1989;111:34-36.

5. Hasan AR, Kabir CS. Fluid flow and heat transfer in wellbores. Textbook Series. SPE, Richardson, Texas; 2002.

6. Taitel Y, Barnea D, Dukler AE. Modelling Flow Pattern Transitions for Steady Upward Gas-Liquid Flow in Vertical Tubes. AIChE J. 1980;26(3):345-354.

7. Nikuradse J. Laws of flow in rough pipes. NACA Tech Mem. 1937;1292.

8. Colebrook FC. Turbulent flow in pipes, with particular reference to the transition region between the smooth and rough pipe laws. J Inst Civ Eng Lond. 1937;11(4):133-156.

9. Aziz K, Govier GW, Fogarasi M. Pressure Drops in Wells producing Oil and Gas. Journal of Canadian Petroleum fv Technology. 1979;38.

10. Beggs HD, Brill JP. A Study of Two-Phase Flow in Inclined Pipes. Journal of Petroleum Technology. 1973;25(5):607-617.

11. Payne GA, Palmer CM, Brill JP, et al. Evaluation of Inclined-Pipe, TwoPhase Liquid Holdup and Pressure-Loss Correlations using Experimental Data. Journal of Petroleum Technology. 1979;31(9).

12. Ansari AM, Sylvester ND, Sarica C, et al. A Comprehensive Mechanistic Model for Upward Two-Phase Flow in Wellbores. SPE Annual Technical Conference and Exhibition. 1994;SPE-20630-MS. 